\title{
Quantitative proteomic comparison of protein differences in different parts of yak meat
}

\author{
Zhongxin YAN ${ }^{1,2,3}$, Wei $\mathrm{LI}^{2}$, Rong $\mathrm{HU}^{2}$, Qingmei $\mathrm{MA}^{4}$, Zhoumin $\mathrm{LU}^{1 \star}$ (D)
}

\begin{abstract}
Proteomics is a powerful tool to understand molecular connections between meat proteins and quality traits. In order to research the total proteome difference and molecular mechanisms related to quality traits in different parts of yak meat. This study was designed to investigate the differences in the proteomes of yak different muscles. In this paper, Tandem Mass Tags (TMT) coupled Liquid chromatography-tandem mass spectrometry (LC-MS/MS) to study the variations of proteome in different parts of yak after it is slaughtered. In total, 88 differentially expressed proteins (DEPs) were identified among striplon (WJR), slivsid (HGT) and chuck (JR). The quality analysis of DEPs showed heat shock proteins (HSPs) and structural proteins could be used as tenderness marker proteins for different parts of yak meat. Myosin and troponin-T may be flavour marker protein in yak meat. The bioinformatics analysis revealed that DEPs are involved in glycolysis, protein structure and phosphorylation. PPI analysis revealed thatmyosin, HSPs and metabolic enzymes may have the potential to be biological markers. This study highlights that the DEPs were responsible for meat quality different.
\end{abstract}

Keywords: yak; proteomics; different parts; meat quality; bioinformatics.

Practical Application: The analysis of proteome provides novel insights for the basic mechanism of different quality in yak meat.

\section{Introduction}

The yak (Bos grunniens) is an important semi wild animal that basically inhabit in the Qinghai-Tibet Plateau and provides the meat, milk, fuel and skin (Zhang et al., 2015). They adapt to hostile environment like hypoxia, low temperature, as well as high radiation, and they feature less fat in body and developed muscle (Hardie et al., 2012; Zuo et al., 2017). In China, yak beef is the most famous and internationally accepted breed for its meat quality. It is considered a health food because of its characteristics and is popular with consumers at home and abroad.

Specifically, meat quality depends on variety, position, age, pressure on the way to slaughterhouse, slaughtering method, post-mortem treatment and so on. In order to obtain high quality meat, researchers have conducted some studies to address these complex issues. The connections between beef quality and number and size of fiber have been examined by Mao et al. (2016), the relation between the growth of cattle and beef quality is studied by He et al. (2017). The impacts of manufacturing and storage means, as well as stock fodder on quality and a comparison between the quality of Angus beef and other variety of cattle have also been analyzed (Taye et al., 2018). Previous researches also have examined the muscle proteome associated with various quality attributes like tenderness, color, and water storage ability (Bjarnadóttir et al., 2012; Wu et al., 2015; Almeida et al., 2015). In beef, the research mainly focuses on the changes of protein expression of gender (Latorre et al., 2003), water-holding capacity during postmortem aging (Almeida et al., 2015; Zuo et al., 2016), phosphoproteomic analysis different altitude yaks (Yang et al.,
2020) protein differences between bovine parts (Wei et al., 2019). However,the employment of TMT in the research of total proteome difference, as well as the molecular mechanism associated with quality features in different parts of yak meat have not been reported.

In order to further study the mechanism of muscle quality difference in different parts of yak meat at cellular and molecular level.The present study applies TMT coupled LC-MS/MS to study the variations of proteome in different parts of yak after it is slaughtered. With the help of GO functional annotation, KEGG pathway investigation and PPI analysis, the study tries to explain protein biomarkers that are related to the distinctions between different parts of yak meat. The analysis of proteome provides novel insights for the basic mechanism of different quality in yak meat.

\section{Materials and methods}

\subsection{Sample}

The author has collected 9 killed bulls-at average live body weights of $248.6 \pm 16.7 \mathrm{~kg}$ and at the age of $36 \pm 2$ months-as samples (WJR, HFT and JR), from a commercial slaughterhouse - Xiahua Hala Food Co., Ltd. in Haiyan City, Qinghai Province, China. It took 60 minutes to gather meat samples after the post-mortem. Every group includes three biological replicates. The researcher has cut about $5 \mathrm{~g}$ of the sample into slight pieces and frozen them with liquid nitrogen ahead of analyzing proteomics. 


\subsection{Total protein extraction}

The samples were chopped with liquid nitrogen, crushed in a $100 \mathrm{mM} \mathrm{NH}_{4} \mathrm{HCO}_{3}$ (pH8), $6 \mathrm{M}$ urea and $0.2 \%$ SDS lysis buffer, and then they are subjected to a five-minute ultrasonication on the ice. The centrifugation of the lysate was at $12,000 \mathrm{~g}$ at $4{ }^{\circ} \mathrm{C}$ and lasted for fifteen minutes. The supernatant was placed in a clean tube. Protein concentration was determined by Bradford protein assay. Reduce the extracts of each sample with $2 \mathrm{mM}$ DTT at $56^{\circ} \mathrm{C}$ for $1 \mathrm{~h}$ and alkylate them in darkness with enough iodoacetamide at room temperature for 1 hour. Next, mix precooled acetone of four times of the volume with the samples through a good vortex and cultivate them at $-20^{\circ} \mathrm{C}$ for no less than two hours. Then centrifuge samples and collect the precipitation. The pellets were dissolved in buffer that includes $6 \mathrm{M}$ urea and $0.1 \mathrm{M}$ triethylammonium bicarbonate (TEAB, $\mathrm{pH}$ 8.5) following twice washing them with cold acetone. The protein concentration was decided again by Bradford protein assay.

\subsection{Peptide preparation}

The supernatant from each sample, containing precisely $0.1 \mathrm{mg}$ of protein, was digested with Trypsin Gold (Promega) at 1:50 enzyme-to-substrate ratio. After $16 \mathrm{~h}$ of digestion at $37^{\circ} \mathrm{C}$, peptides were desalted with $\mathrm{C}_{18}$ cartridge to remove the high urea, and desalted peptides were dried by vacuum centrifugation.

\subsection{TMT labeling of peptides}

According to instructions, TMT6/10-plex reagents (TMT6/10plex ${ }^{\text {met }}$ Isobaric Label Reagent Set, Thermo Fisher) were employed to label the desalinated peptides. One unit of labeling reagent was used for labeling $0.1 \mathrm{mg}$ peptide. The dissolution of peptides was achieved in $100 \mu \mathrm{L} 0.1$ TEAB. In addition, the dissolution of labeling reagent was finished in $41 \mu \mathrm{L}$ acetonitrile. Finish the reaction with ammonium hydroxide after cultivating them for one hour. The different labeled peptides were uniformly mixed, and desalted them by peptide desalting spin columns (Thermo Fisher, 89852).

\subsection{HPLC fractionation}

TMT-labeled peptide mix was fractionated using a $\mathrm{C}_{18}$ column (Waters BEH C ${ }_{18} 4.6 \times 250 \mathrm{~mm}, 5 \mu \mathrm{m}$ ) on a Rigol L3000 HPLC operating at $1 \mathrm{~mL} / \mathrm{min}$, the column oven was set as $50^{\circ} \mathrm{C}$. Mobile phases $\mathrm{A}$ ( $2 \%$ acetonitrile, adjusted $\mathrm{pH}$ to 10.0 using ammonium hydroxide) and $\mathrm{B}$ (98\% acetonitrile, adjusted $\mathrm{pH}$ to 10.0 using ammonium hydroxide) were used to develop a gradient elution. The solvent gradient was set as follows: $3 \% \mathrm{~B}, 0 \mathrm{~min} ; 3-5 \% \mathrm{~B}$, $10 \mathrm{~min} ; 5-20 \%$ B, $20 \mathrm{~min} ; 20-40 \%$ B, 18 min; 40-50\% B, 2 min; $50-70 \%$ B, 3 min; $70-100 \%$ B, 1 min; $100-0 \%, 4$ min, $0 \%$ B, $12 \mathrm{~min}$. The elutions were monitored at UV $214 \mathrm{~nm}$, collected for a tube per minute and merged into 10 fractions finally.All fractions were dried under vacuum and reconstituted in $0.1 \%$ $(\mathrm{v} / \mathrm{v})$ formic acid (FA) for subsequent analyses.

\subsection{LC-MS/MS analysis}

The present research employed EASY-nLC ${ }^{\mathrm{TM}} 1200$ UHPLC system (Thermo Fisher) and Orbitrap Q Exactive HF-X mass spectrometer (Thermo Fisher) which is operated in data-dependent acquisition (DDA) pattern to analyze shotgun proteomics. The sample volume comprises total peptide of $2 \mu \mathrm{g}$ injected into the self-made $(2 \mathrm{~cm} \times 100 \mu \mathrm{m}, 5 \mu \mathrm{m})$. A linear gradient of TMT- 6 plex was used from 5 to $100 \%$ eluent B $(0.1 \%$ FA in $80 \%$ to isolate the peptide on a self-made analytical column $(15 \mathrm{~cm}$ $\times 150 \mu \mathrm{m}, 1.9 \mu \mathrm{m})$ at a flow rate of $600 \mathrm{NL}$ per min in eluent $\mathrm{A}$ (water $0.1 \% \mathrm{FA}$ ) in 90 minutes. The gradient of solvent is: 5-10 percent of B, 2 minutes; $10-40$ percent of $B, 80$ minutes; 40-55 percent of B, 2 minutes; $55-90$ percent of B, 1 minute; 90-100 percent of $B, 5$ minutes; or employing a linear gradient of TMT10-plex from $5 \%$ to $100 \%$ eluate B $(0.1 \%$ FA in $80 \%$ $\mathrm{ACN})$ in eluent $\mathrm{A}\left(0.1 \% \mathrm{FA}\right.$ in $\left.\mathrm{H}_{2} \mathrm{O}\right)$ within 120 minutes at a flow velocity of $600 \mathrm{~nL} / \mathrm{min}$. Correspondingly, the gradient of solvent is: $5-10$ percent of $\mathrm{B}, 2$ minutes; $10-40$ percent of $\mathrm{B}$, 105 minutes; $40-55$ percent of B, 5 minutes; $55-90$ percent of B, 3 minutes; $90-100$ percent of $B, 5$ minutes. The spray voltage is $2.3 \mathrm{kV}$, meanwhile the capillary temperature is $320^{\circ} \mathrm{C}$, at which the Q Exactive HF-X mass spectrometer is performed in a positive mode with a spray. The scanning range of full MS is from $350 \mathrm{~m} / \mathrm{z}$ to $1500 \mathrm{~m} / \mathrm{z}$ and obtained at the resolution of $60000(200 \mathrm{~m} / \mathrm{z})$ with the target value of automatic gain control (AGC) of $3 \times 10^{6}$. The maximum ion implantation time is $20 \mathrm{~ms}$. With a higher energy collisional dissociation (HCD), a resolution of $15000(200 \mathrm{~m} / \mathrm{z})$, a AGC target value of $1 \times 10^{5}$, the standardized collision energy of $32 \%$, the intensity threshold of $8.3 \times 10^{3}$, the maximum ion implantation time of $45 \mathrm{~ms}$, and the dynamic exclusion parameter of 20 s are adopted to filtrate forty most abundant precursor ions from full MS scan.

\subsection{The identification and quantization of protein}

The search engine seeks the result spectrum of each component according to the UniProt database: Proteome Discoverer 2.2 (PD 2.2, Thermo). The parameters searched are: a mass tolerance of precursor ion scanning is $10 \mathrm{ppm}$, and that of product ion scanning is $0.02 \mathrm{Da}$. Carbamidomethyl is designated as a fixed modification in PD 2.2. Methionine oxidation, $\mathrm{N}$-terminal acetylation as well as TMT of lysine were designated as variable modifications in PD 2.2. At most two miscleavage sites are acceptable.To identify protein, when the FDR is under $1.0 \%$, protein containing at least one unique peptide is recognized at protein level and the peptide respectively. Proteins containing similar peptides and could not be distinguished based on MS/ MS analysis were grouped separately as protein groups.Reporter Quantification (TMT) is employed for TMT quantification. Mann-Whitney Test is adopted to study the results of protein quantitation. Different expression protein (DEP) was sifted by $\mathrm{P}<0.05$ and $\mathrm{FC}>1.2$ or $\mathrm{FC}<0.83$ [fold change, $\mathrm{FC}$ ]

\subsection{The functional analysis of protein and DEP}

The investigation of GO (Gene Ontology) was carried out by employing interproscan- 5 program against non-redundant protein database, which contains ProDom, Pfam, ProSiteProfiles, SMART, PANTHER, PRINTS (Jones et al., 2014) and Kyoto Encyclopedia of Genes and Genomes (KEGG), to examine pathways and protein families. The STRING-db server (STRING, 2020) according to relative species was adopted to forecast the 
possible interaction partners. This database is used to predict the possible interaction partners. It is a database of predicted and known protein interactions (Franceschini et al., 2012). The enrichment investigation of KEGG and GO is performed with the employment of enrichment pipeline (Huang et al., 2009).

\section{Results and discussion}

\subsection{Protein identification and quantification}

There are 379354 LC-MS/MS spectras that matched to the known spectras, 2087 proteins and 17698 peptides were recognized by $1 \%$ FDR. Most of the identified proteins had molecular weights in the range of $10-70 \mathrm{kDa}$ (Figure 1A). Approximately 80 percent of the peptides was 6-23 amino acids in length (Figure 1B). In addition, near 80 percent of proteins contained at most 2 unique peptides. The sequence coverage of the identified proteins was relatively low, and near 75 percent of them are lower than $30 \%$ (Figure 1C).

\subsection{Analysis of Differentially Expressed Proteins (DEPs)}

Of the 2087 proteins, the value of $\mathrm{Q}<0.05$ and that of $\mathrm{FC}>1.2$ or $\mathrm{FC}<0.83$ were determined to be DEPs. The number of DEPs was 34 in the WJR/JR comparison group, 40 in the WJR/HGT comparison group, and 25 in the JR/HGT comparison group. 13, 28 and 23 DAPs among the DEPS were up-regulated, whereas 21,12 and 3 DAPs were downregulated (Figure 2).

The DAPs that may have an impact on yak meat quality can be seen in Table 1.In WJR/JR comparison groups, these DEPs are mainly myosin, NADH dehydrogenase, troponin and their related proteins. In WJR/HGT, these DEPs are mainly myosin,

A

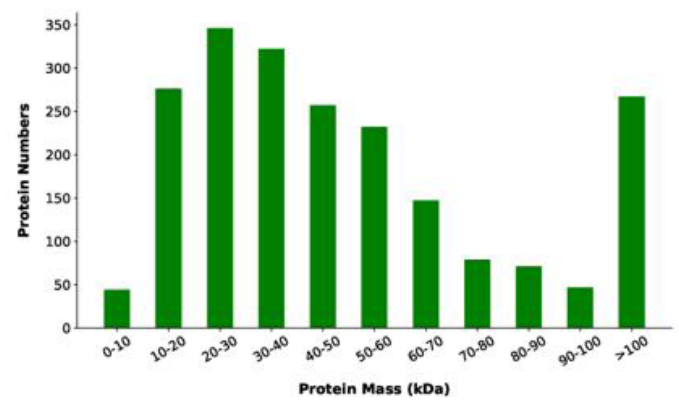

B

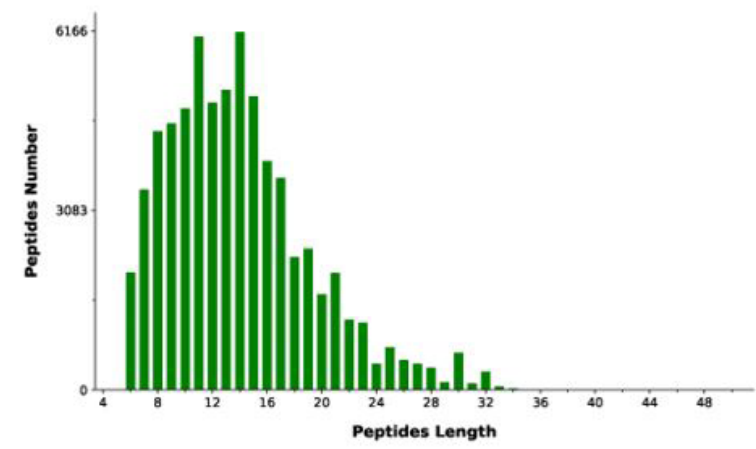

$\mathrm{C}$

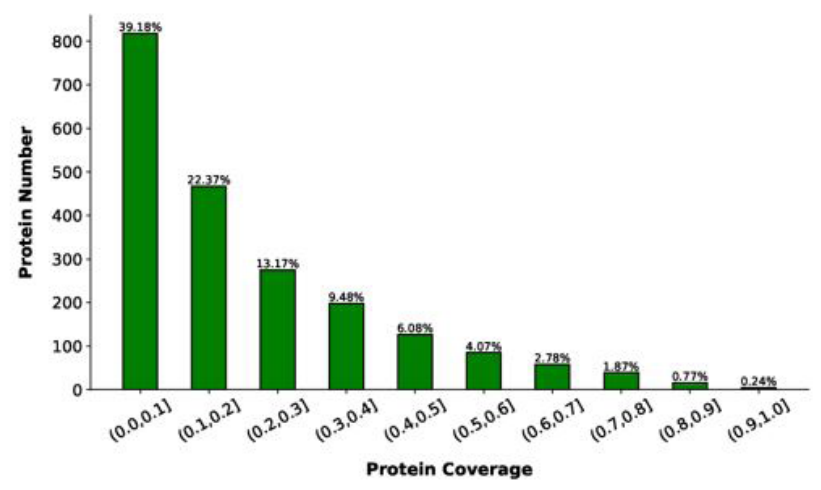

Figure 1. Results of the proteome analysis. (A) Protein mass; (B) Proteinlength; (C) coverage distribution. 


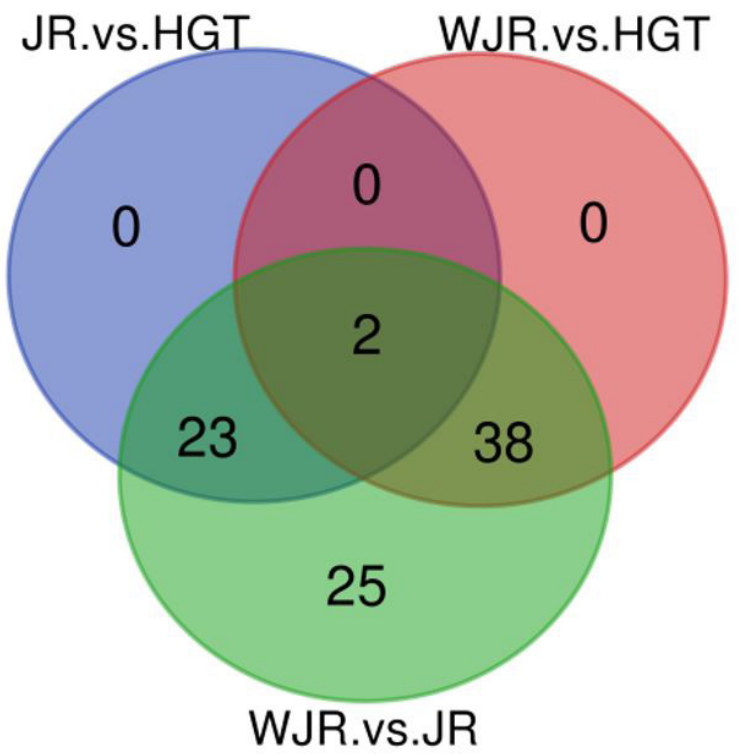

Figure 2. Venn diagram of DEPs in different parts of yak meat.

Table 1. DEPs for different parts of yak meat.

\begin{tabular}{|c|c|c|c|}
\hline Accession & Description & Gene & FC \\
\hline \multicolumn{4}{|l|}{ WJR.vs.JR } \\
\hline A0A3Q1LGQ8 & Nebulin & NEB & 2.009 \\
\hline A0A3Q1N7G0 & Ryanodine receptor 1 & RYR1 & 0.759 \\
\hline A0A3Q1LQC6 & Myosin binding protein $\mathrm{C}$, fast type & MYBPC2 & 1.313 \\
\hline Q08DP0 & Phosphoglucomutase-1 & PGM1 & 1.291 \\
\hline A6QPB5 & PGM1 protein & PGM1 & 1.222 \\
\hline A0A452DJI6 & Troponin T3, fast skeletal type & TNNT3 & 0.631 \\
\hline D4QBB4 & Globin A1 & HBB & 0.650 \\
\hline P48644 & Retinal dehydrogenase 1 & ALDH1A1 & 1.221 \\
\hline F6RP72 & Tubulin alpha chain & LOC100295712 & 0.695 \\
\hline B3IVN4 & M1-type pyruvate kinase (Fragment) & PKM & 1.292 \\
\hline Q0VBZ1 & Myosin binding protein $\mathrm{H}$ & МYBPH & 1.891 \\
\hline P01966 & Hemoglobin subunit alpha & HBA & 0.691 \\
\hline Q1JQB0 & Collagen type VI alpha 2 chain & COL6A2 & 0.661 \\
\hline P10790 & Fatty acid-binding protein, heart & FABP3 & 0.683 \\
\hline F6QJJ8 & Progesterone receptor membrane component 2 & PGRMC2 & 1.326 \\
\hline P00129 & Cytochrome b-c1 complex subunit 7 & UQCRB & 0.774 \\
\hline Q58DW1 & Fatty acid binding protein 3 & FABP3 & 0.693 \\
\hline P62935 & Peptidyl-prolyl cis-trans isomerase A & PPIA & 1.641 \\
\hline F1MWG1 & Oxoglutarate dehydrogenase like & OGDHL & 0.822 \\
\hline Q02369 & NADH dehydrogenase [ubiquinone] 1 beta subcomplex subunit 9 & NDUFB9 & 0.802 \\
\hline Q8HXG6 & NADH dehydrogenase [ubiquinone] 1 alpha subcomplex subunit 11 & NDUFA11 & 0.797 \\
\hline A0A3Q1M3K7 & Ras-related protein Rab-7a & RAB7A & 1.248 \\
\hline A0A3Q1LK04 & Ubiquitin carboxyl-terminal hydrolase & UCHL1 & 1.483 \\
\hline P10462 & Protein S100-A2 & S100A2 & 1.658 \\
\hline G1K1S9 & NADH dehydrogenase [ubiquinone] 1 beta subcomplex subunit 4 & NDUFB4 & 0.825 \\
\hline E1BEM3 & Uncharacterized protein & CDV3 & 0.819 \\
\hline F1N3I4 & Myoferlin & MYOF & 0.660 \\
\hline A4FUC7 & CCDC127 protein & CCDC127 & 0.684 \\
\hline A0A3Q1M453 & Coiled-coil-helix-coiled-coil-helix domain-containing protein 7 & $\mathrm{CHCHD7}$ & 0.791 \\
\hline F1MQ31 & Brevican core protein & BCAN & 0.761 \\
\hline Q2KID7 & Oligosaccharyltransferase complex subunit OSTC & OsTC & 0.820 \\
\hline A0A3Q1N9H8 & Uncharacterized protein & DNAJA3 & 0.797 \\
\hline
\end{tabular}


Table 1. Continued...

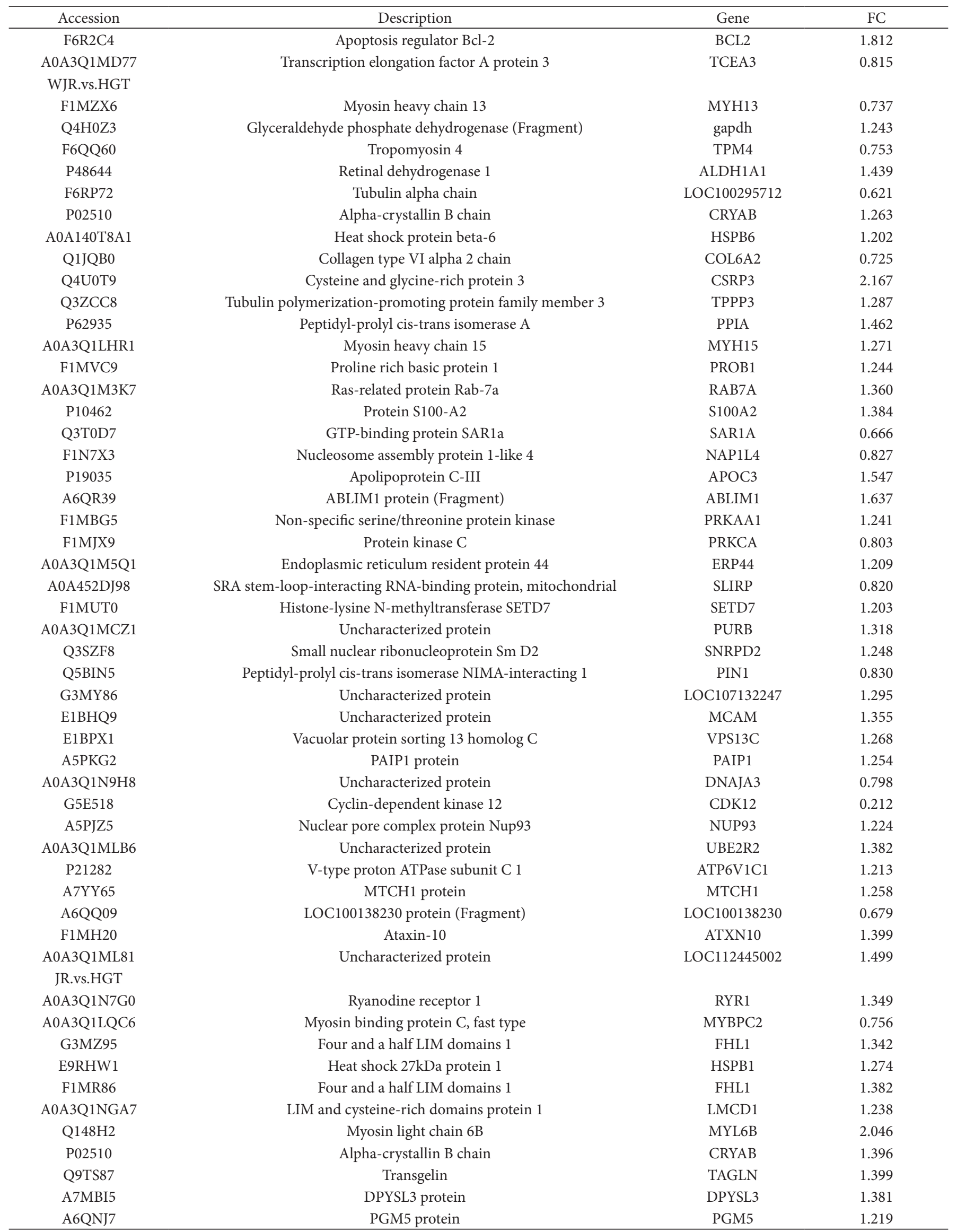


Table 1. Continued...

\begin{tabular}{cccc}
\hline Accession & Description & Gene & FC \\
\hline Q3MHY1 & Cysteine and glycine-rich protein 1 & KRT5 & 1.268 \\
Q5XQN5 & Keratin, type II cytoskeletal 5 & -- & 1.368 \\
P52898 & Dihydrodiol dehydrogenase 3 & ANKRD2 & 1.219 \\
F1MX12 & Ankyrin repeat domain 2 & KRT14 & 1.543 \\
F1MC11 & Keratin, type I cytoskeletal 14 & DNAJA4 & 1.268 \\
F1N6Q0 & DnaJ heat shock protein family (Hsp40) member A4 & ARPP19 & 1.320 \\
Q28055 & cAMP-regulated phosphoprotein 19 & RAB5B & 0.825 \\
F1MNI4 & RAB5B, member RAS oncogene family & CALU & 1.232 \\
F1N3H1 & Calumenin & HEBP2 & 1.225 \\
E1BFP1 & Heme binding protein 2 & CCDC58 & 2.105 \\
A4FU1 & Coiled-coil domain-containing protein 58 & MYDGF & 1.219 \\
P62248 & Myeloid-derived growth factor & ADO & ATXN10 \\
F3MZK0 & 2-aminoethanethiol dioxygenase & Ataxin-10 & 1.290 \\
\hline
\end{tabular}

tubulin, collagen, tropomyosin, heat shock protein (HSPB6) and their related proteins. In JR/HGT, these DEPs are mainly myosin, heat shock protein (HSPB1), keratin and their related proteins.

\section{Structural proteins}

Previous studies have shown that the composition of muscle protein heavily affects the conversion of muscle to meat, and consequently affects the meat quality (Paredi et al., 2012). Myofibrillar proteins like troponin-T, myosin heavy chain, myosin light chain and tropomyosin, play an important role in the quality of meat and influence parameters such as water holding ability (Di Luca et al., 2013; Te Pas et al., 2013) and tenderness (Rosa et al., 2018). Nebulin, tropomyosin, troponin and myosin may be related with specifying and stabilizing the highly ordered construction of muscles, while tropomyosin and nebulin can function as "protein regulators" to accurately define the fitting of myosin filaments (Mora et al., 2010; Gallego et al., 2015). Drip loss, WBSF, meat color and protein solubility of yak meat have been effected by different parts (Zuo et al., 2016). In the present study, some of the DEPs identified are related to meat quality, involving structural proteins, troponin and myosin (Polati et al., 2012; Ouali et al., 2013) that are processed with enzymatic proteolysis during postmortem, particularly with cathepsins, calpain-1and caspase system (Li et al., 2017).

Myosin light chains are related with and regarded as previous predictors of postmortem proteolysis associated with tenderness in various varieties of beef like Charolais, Blonde d'Aquitane, Angus, Nellore and Norwegian (Rosa et al., 2018; Guillemin et al., 2011). On a basis of previous researches, and myosin light chain (Mora et al., 2011) and troponin-T, myosin heavy chain (Mora et al., 2010) are tightly associate with the development of flavor. In addition, postmortem degradation of troponin proteins may impair the constitution of muscle cells and be related to the tenderness of beef (Contreras-Castillo et al., 2016; Wright et al., 2018).

In this project, the Cytoskeleton-related proteins like myosin, tubulin, collagen, tropomyosin and tubulin were different in the three parts of yak meat, so the ultrastructure of yak meat can be affected by different parts. These studies suggest that these
Cytoskeleton-related proteins pertain to the same family, they may act on the meat color,tenderness and water holding ability on their own in different parts of yak meat.

\section{Metabolic enzymes and stress related proteins}

Glyceraldehyde-3-phosphate dehydrogenase, as an important enzyme in glycolysis pathway, promotes the oxidation as well as the phosphorylation of substrate aldehydes to acyl phosphates, leading to the generation of adenosine triphosphate by the chain of electronic transportation (Mora et al., 2011; Gallego et al., 2016). The presentation of NADH dehydrogenase of present study were different in the three groups.

According to Xu et al. (2016), heat shock proteins is a biological indicators of heat stress generated by the reaction of cells to heat shock. The function of HSPs may help to keep the integrity ofmuscle cell and protect against the proteolysis of myofibrillar (Picard et al., 2014; Malheiros et al., 2019). Previous studies have reported that HSP27, HSP20, HSP40, HSP70 and other chaperone proteins also relate to the tenderness of meat in various kind of muscles and variety of cattle (Polati et al., 2012; D'Alessandro \& Zolla, 2013). The negative correlation between HSPB1 and the tenderness of beef was put forward in researches of gene and protein expression (Kim et al., 2008; Malheiros et al., 2018). A positive relation between HSP27 (HSPB1), HSP20 (HSPB6) and tenderness of LT muscle in Blond d'Aquitaine, Limousin and Aberdeen Angus cattle was also found out by Picard et al. (2014). These studies suggest that although these HSPs pertain to the same family, they may act on the tenderness on their own in the three groups of yak meat. The presentation of HSP27 (HSPB1), HSP20 (HSPB6) and HSP40 of present study were different in the three groups.

These overlapped DAPs change with different parts and may be potential biomarkers of protein tightly associated with the quality of different parts. In our study, myosin, troponin T, and HSP family associated with water retention, tenderness, meat color and protein solubility.Because of the different parts of yak meat, there were some differences in meat quality mechanism among the sample groups. 


\subsection{GO functional classification of DEPs}

DEPs can be divided into three types: molecular function (MF), biological process (BP) and cellular component (CC). To determine the functional information of all DEPs, GO enrichment analysis was performed (Figure 3). After the enrichment of GO, most of the expression of DEPs in the three groups was different.
$\mathrm{BP}$ is a key category for metabolic pathways, and six significantly BP groups (oxygen transport, muscle contraction, myoblast fusion, regulation of striated muscle contraction, negative regulation of apoptotic and carbohydrate metabolic) were observed in the WJR/JR comparison group (Figure $3 \mathrm{~A}$ ). Also six significantly BP groups (chromatin organization, microtubule bundle formation, microtubule polymerization,

A

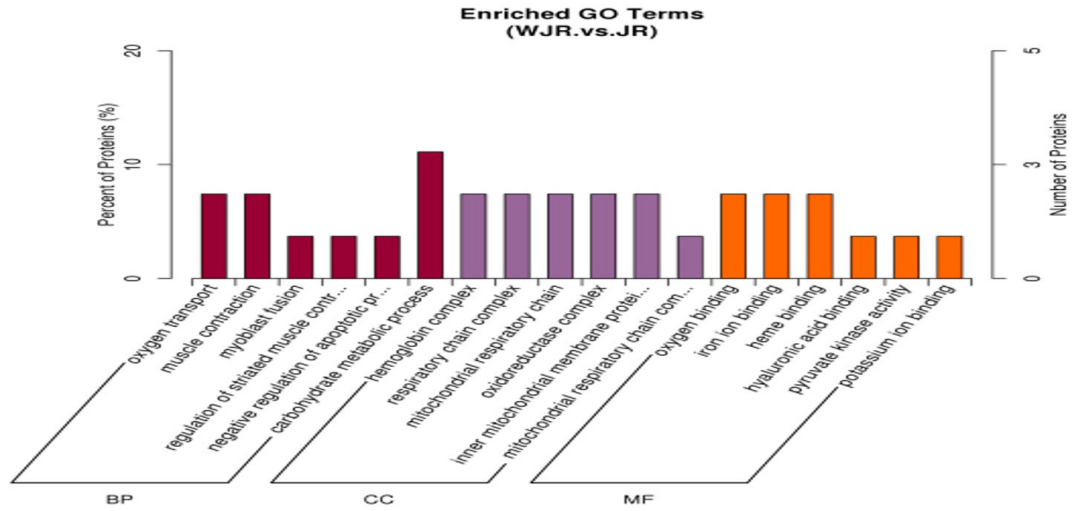

B

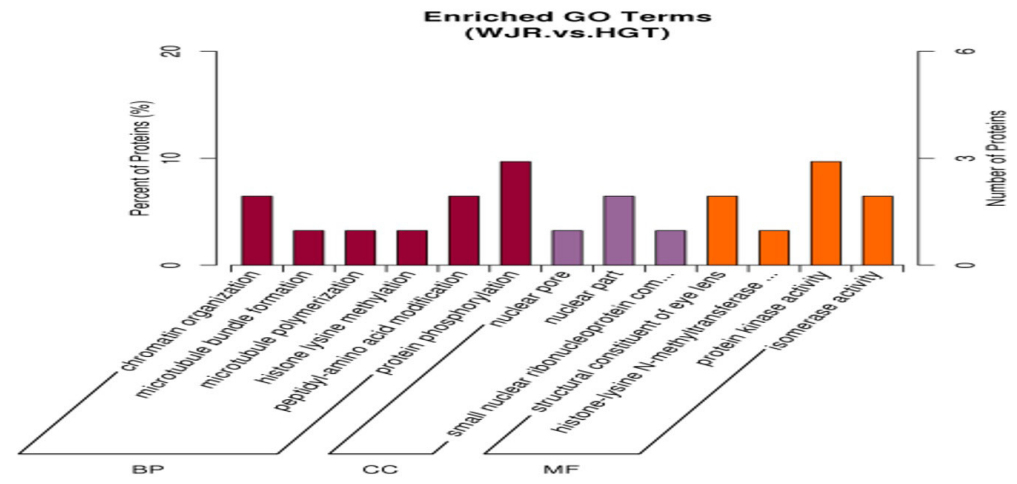

C

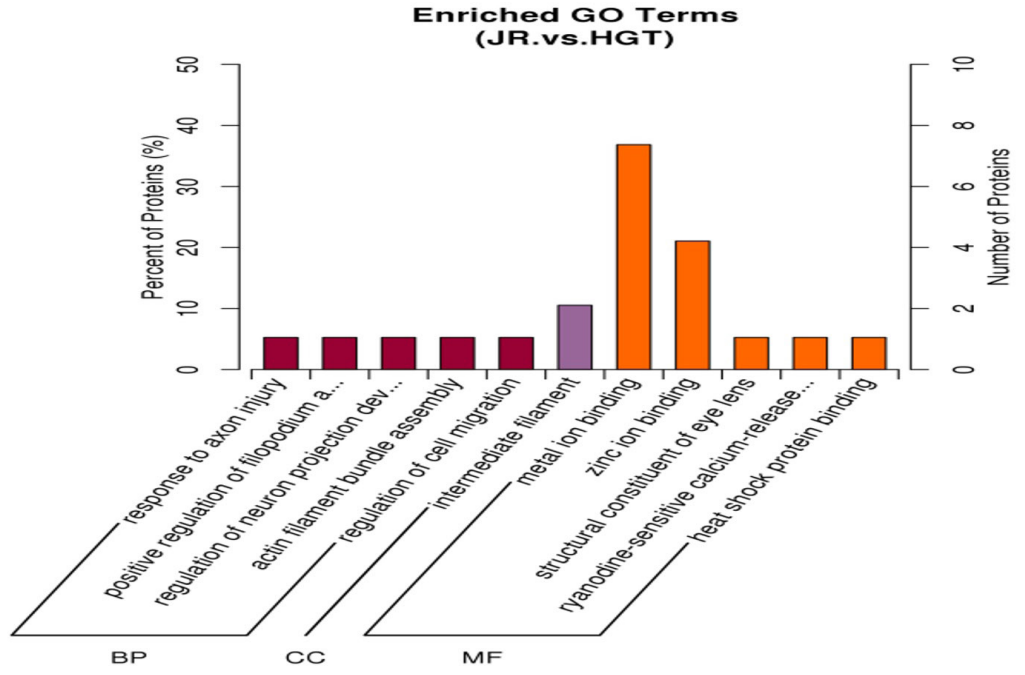

Figure 3. Gene ontology (GO) classification of differentially expressed proteins (DEPs). (A) in the WJR/JR comparison group; (B) in the WJR/ HGT comparison group; (C) in the JR/HGT comparison group. 
histone lysine methylation, peptidyl-amino acid modification and protein phosphorylation) were observed in the WJR/HGT comparison group (Figure 3B). In the JR/HGT contrast group, five significant BP groups (axon injury, positive regulation of filopodium assembly, regulation of neuronal projection development and actin filament) were observed (Figure 3C). DEPs are mainly proteins involved in oxygen transport, muscle contraction, carbohydrate metabolic, chromatin organization, peptidyl-amino acid modification and protein phosphorylation in the three groups. These biological processes are primary focused on muscle contraction, metabolic and phosphorylation.

In the cell component classification, six significantly CC groups (hemoglobin complex, respiratory chain complex, oxidoreductase complex, mitochondrial respiratory chain, mitochondrial membrane protein complex as well as mitochondrial respiratory chain complex III) were observed in the WJR/JR comparison group (Figure 3A). Three significantly CC groups(nuclear pore, nuclear part and small nuclear ribonucleoprotein complex) were observed in the WJR/HGT comparison group (Figure 3B). While only one significantly CC group (intermediate filament) was observed in the JR/HGT comparison group (Figure 3C). These cellular component are primary focused on mitochondrial and proteins complex. Mitochondria can influence the redox status of myoglobin. It is found that the reduction ability of metmyoglobin mainly relies on the electrons which is produced by mitochondria and the NADH that is produced by dehydrogenase (Faustman et al., 2010). However, according to Joseph et al. (2015), the NADH dehydrogenase primarily centers in down-regulated proteins. Tang et al. (2005) also pointed out that the mitochondria also affect the stabilizing of color and the forming of mechanism of flesh color through the reduction of metmyoglobin and oxygen partial pressure.

In the molecular function classification, six significantly MF groups (oxygen binding, iron ion binding, heme binding, hyaluronic acid binding, pyruvate kinase activity and potassium ion binding) were observed in the WJR/JR comparison group (Figure 3A). Four significantly MF groups(structural constituent of eye lens, histone-lysine $\mathrm{N}$-methyltransferase activity, protein kinase activity and isomerase activity) were observed in the WJR/HGT comparison group (Figure 3B). While five significantly MF groups (structural constituent of eye lens, ryanodine-sensitive calcium-release channel movements, binding of metal ion, binding of zinc ion, and heat shock protein binding) was observed in the JR/HGT comparison group (Figure 3C). The functional investigation of molecular showed that in the three groups, metabolizing enzymes and binding proteins were dominant, indicating that they have significant effect on the variations of quality of various parts of meat. Studies have shown that as a rate-limited glycolytic enzyme, pyruvate kinase has two subtypes in common muscle. According to Zhang \& Liu (2017), pyruvate kinase remains highly active in PSE meat and are ascribed to the likely post-translational modification of these proteins.

The GO analysis further demonstrated that these DEPs have different biological functions and were responsible for meat quality different. Therefore, the different quality of meat may be caused by the change in the function of signal transduction and the expression of transcription regulatory genes.

\subsection{KEGG pathway analysis of DEPs}

KEGG pathway was employed to find the particular biological event resulting in varying meat quality features. Generally, different proteins work together to function biologically. As shown In Figure $4 \mathrm{~A}$, in the group pf WJR/JR the top 20 pathways were assigned to DEPs and ten pathways were greatly enriched in both groups ( $\mathrm{P}$-value $<0.05)$. The pathway terms showing significance were:Malaria, Galactose metabolism, African trypanosomiasis, Purine metabolism, nucleotide sugar metabolism, Amino sugar, Pentose phosphate, Parkinson's disease, Starch, Retinol metabolism, sucrose metabolism as well as Glycolysis/Gluconeogenesis. In Figure 4B, 5 were significantly enriched in the WJR/HGT group ( $\mathrm{P}$-value $<0.05)$. The pathway terms showing significance were: mTOR signaling, Tight junction, Retinol metabolism, Phagosome and Longevity regulating pathway- multiple species. In Figure 4C, 8 were greatly fertilized in the groups of JR/HGT (P-value $<0.05)$. The pathway terms showing significance were: Jak-STAT signaling, Taurine and hypotaurine metabolism, Steroid hormone biosynthesis, Ovarian steroidogenesis, Amoebiasi, Oxytocin signaling, Hypertrophic cardiomyopathy (HCM) and Dilated cardiomyopathy (DCM).

Even though the pathways enriched in every part are varying, the main function of these pathways were engaged in "Jak-STAT signaling", "mTOR signaling", Tight junction, Glycolysis/Gluconeogenesis and "Malaria". In previous studies, the yak signal pathway associated with hypoxia contained the various proteins of HIF hypoxia signal pathways (Yang et al., 2020), and the expression of HIF1 is inhibited by the mTOR inhibition (Harada et al., 2009). Glycolysis may be the most significant pathway to form the quality of meat, because it affects the variation of $\mathrm{pH}$ value, and the variation of $\mathrm{pH}$ value directly or indirectly adjusts the significant properties of meat quality like water holding ability, color of meat, tenderness and so forth (Chen et al., 2019). The expression of meat quality and myofibrillar proteins is influenced by the glycolysis (Wei et al., 2019; Larsson et al., 2012). One glucose molecule is metabolized into two pyruvate molecules in the glycolysis pathway, producing two ATP molecules, lactate and decreasing $\mathrm{pH}$ value of muscle (Chen et al., 2019). Moreover, it can destroy the stability of the color of meat and affectthe stability of myoglobin redox (Suman \& Joseph, 2013). The closely connected pathway can indirectly impact the intercellular space of the muscleand further improve the rigidity of muscle (Chen et al., 2020).

The KEGG pathway analysis further demonstrated that metabolic pathway of these DEPs may be responsible for meat quality different. Therefore, these DEPs primarily effect the different part meat quality.

\subsection{Protein-protein interaction analysis}

Zuo et al. (2017) stated that generally proteins interact with each other to function differently. The protein-protein interaction (PPI) networks are further established for DEPs using the STRING database. These interactions contain indirect functional connections and direct physical connections.

In Figure 5A (WJR/JR), Figure 5B (WJR/HGT) and Figure 5C (JR/HGT), the blue nodes indicate the down-regulated 
$\mathbf{A}$

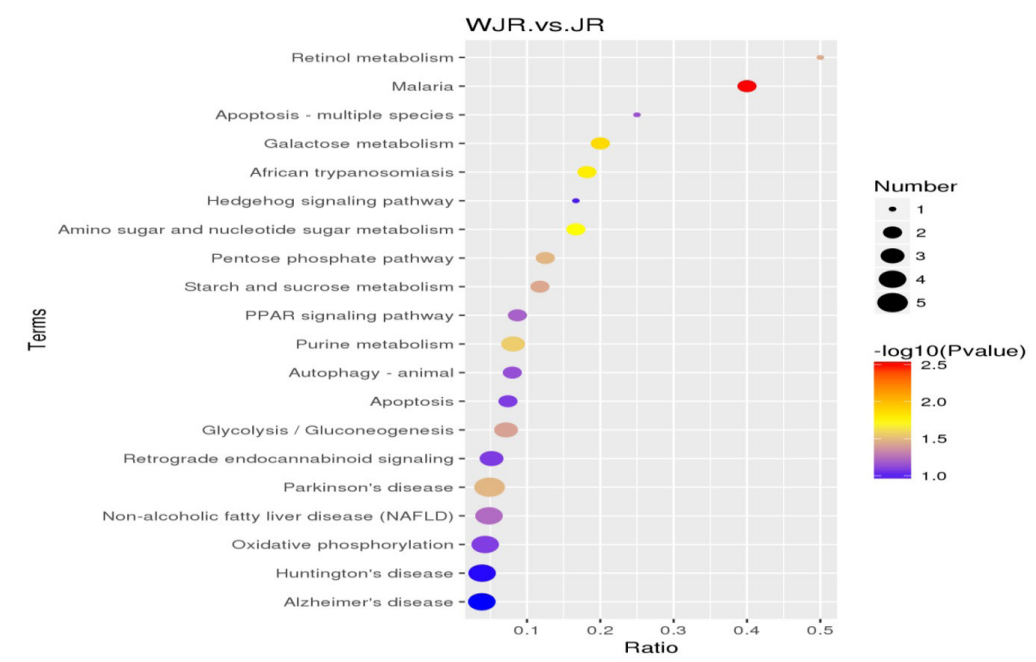

B

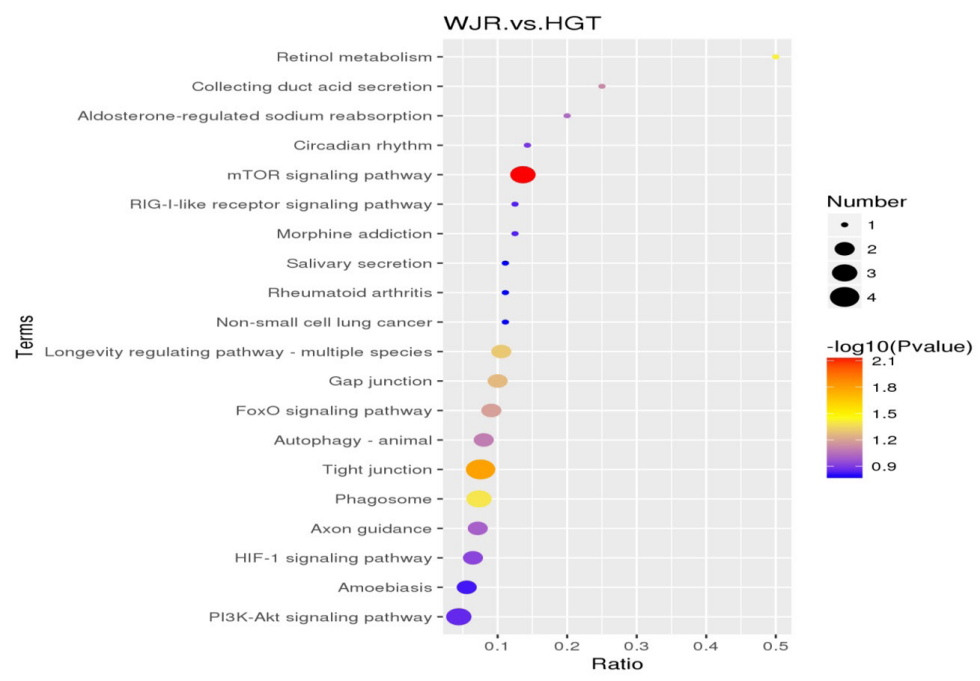

C

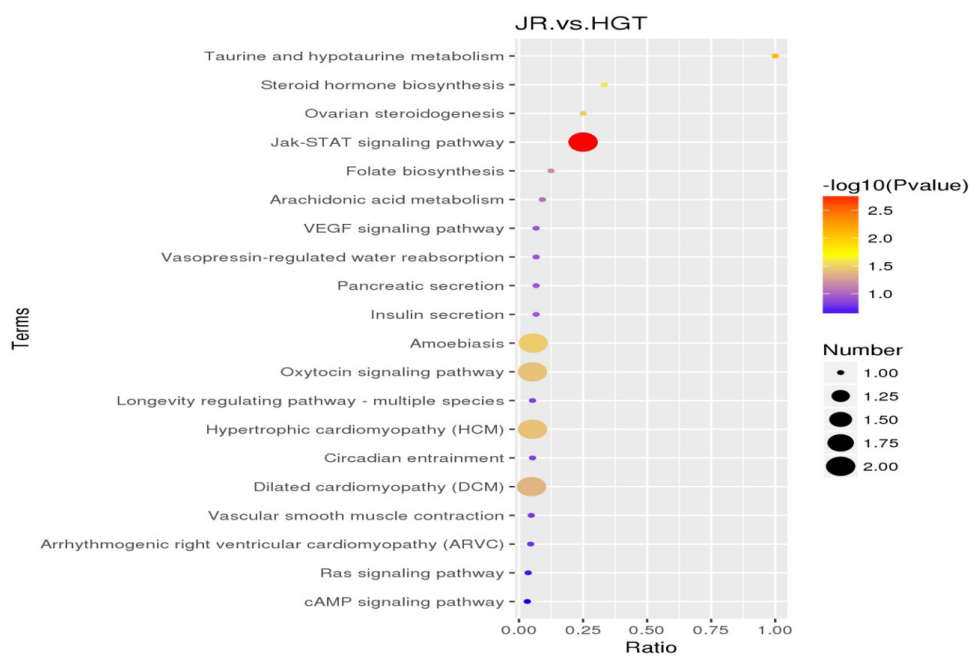

Figure 4. Top 20 KEGG pathway enrichment of differentially expressed proteins (DEPs). (A) in the WJR/JR comparison group; (B) in the WJR/ HGT comparison group; (C) in the JR/HGT comparison group. 
A

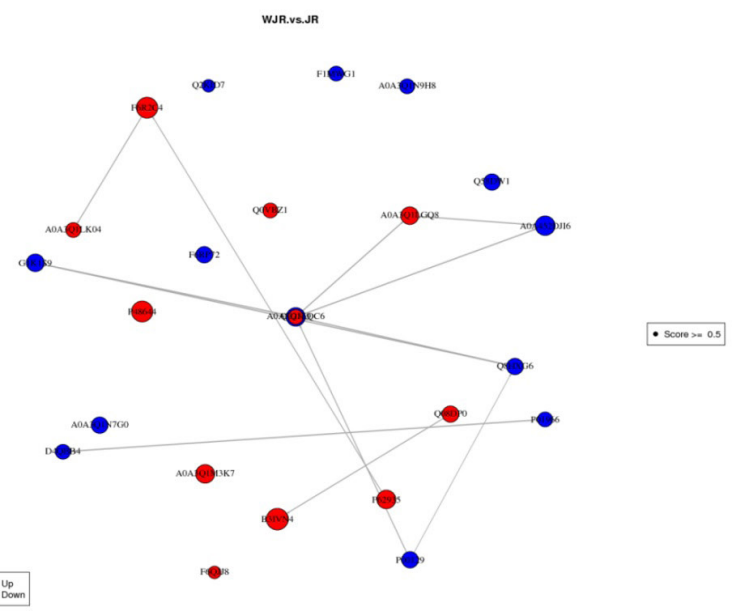

B

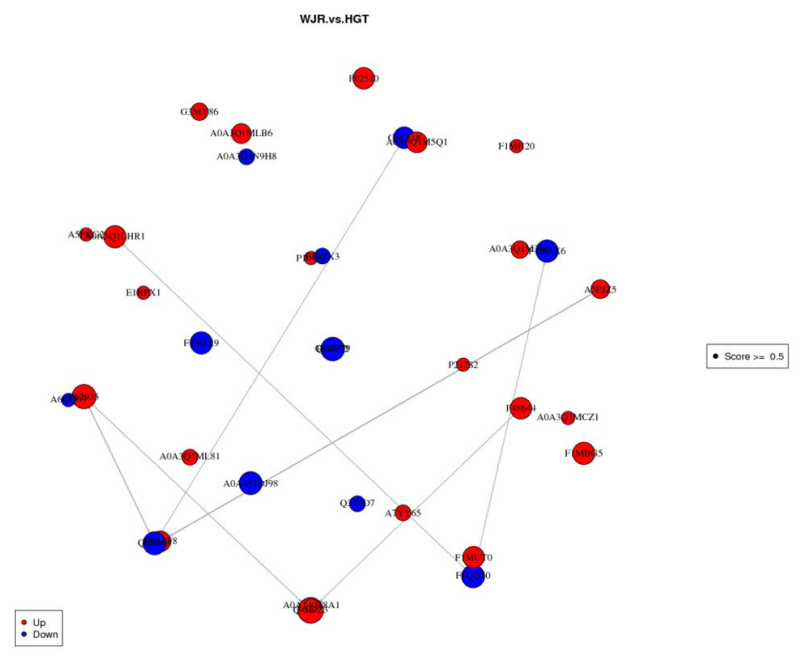

C

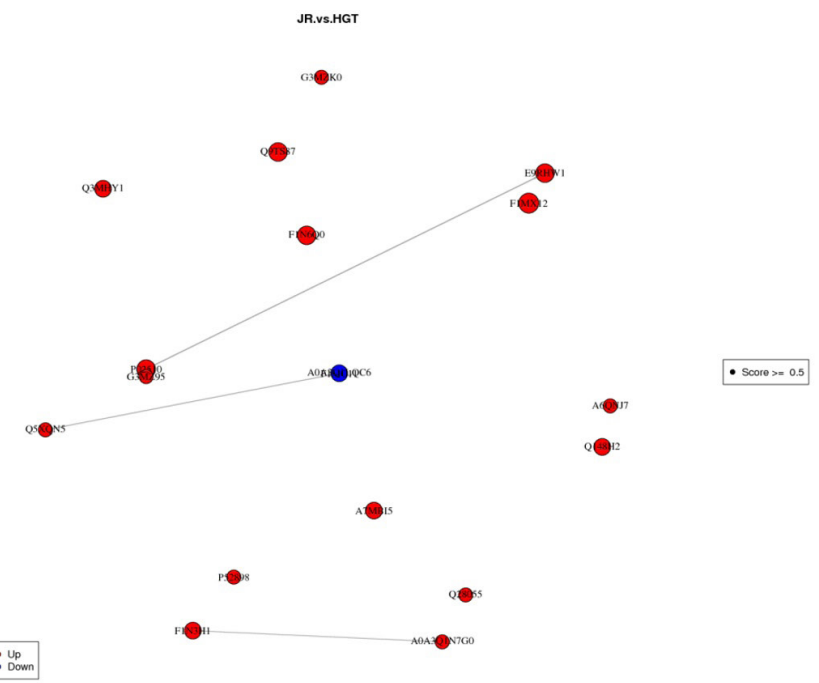

Figure 5. Protein-protein interaction analysis. (A) in the WJR/JR comparison group; (B) in the WJR/HGT comparison group; (C) in the JR/HGT comparison group. 
proteins and the red nodes indicate the up-regulated protein. Proteins (A0A3Q1LQC6, G1K1S9 and Q8HXG6) that are from the skeleton interacted. In WJR/JR comparison, which revealed that there was a strong interaction between these proteins, which functioned as a controller in the biochemical variations. In WJR/HGT contrast, it is shown that Q3SZF8 and Q5BIN5 proteins greatly influenced the regulation of the quality of meat. While in JR/HGT comparison, the results showed that some proteins cannot directly interact with others. However, they still help to develop the meat quality.

The PPI further demonstrated that these primarily proteins from muscle structural proteins, matabolic enzyme and mitochondria were responsible for meat quality different. In previous studies, it was put forward that there was a direct relation between the muscle structural proteins and the formation of meat tenderness (Lonergan et al., 2010). In addition, it is found that glycolytic enzymes were related to the stability of the color of Longissimus lumborum (Ll) and Psoas major muscles (Wu et al., 2015), and glycolytic protein has a positive correlation with rednessin beef muscles (Joseph et al., 2012). Therefore, these proteins are of great significance to the formation of meat quality. Nevertheless, most proteins are not linked to other proteins, which are probably caused by the association of most proteins with database that is still unknow.

\section{Conclusion}

The present study examines the differences of protein in yak meat using TMT technology. A total of 2087 proteins and 17698 peptides were recognized with $1 \%$ FDR. The number of DEPs was 34 in the WJR/JR comparison group, 40 in the WJR/HGT comparison group, and 25 in the JR/HGT comparison group. The bioinformatic investigation showed that DEPs are concerned with glycolysis, protein structure and phosphorylation. NADH and SDH may be the potential biomarkers for colour.HSPs could be employed as tenderness marker proteins for various parts. Maybe myosin and troponin- $\mathrm{T}$ are the flavor marker protein of beef. PPI analysis revealed that myosin, HSPs and metabolic enzymes might be the biological markers and were responsible for meat quality different.These DEPs may be responsible for meat quality different from parts of yak.

\section{Acknowledgements}

This work was supported by the Qinghai Science and Technology Plan Projects (2016NKA7) and the Fundamental Research Projects of Academy of Animal Sciences and Veterinary Medicine of Qinghai University (MKY201802).

\section{References}

Almeida, A. M., Bassols, A., Bendixen, E., Bhide, M., Ceciliani, F., Cristobal, S., Eckersall, P. D., Hollung, K., Lisacek, F., Mazzucchelli, G., McLaughlin, M., Miller, I., Nally, J. E., Plowman, J., Renaut, J., Rodrigues, P., Roncada, P., Staric, J., \& Turk, R. (2015). Animal board invited review: advances in proteomics for animal and food sciences. Animal, 9(1), 1-17. http://dx.doi.org/10.1017/S1751731114002602. PMid:25359324.
Bjarnadóttir, S. G., Hollung, K., Høy, M., Bendixen, E., Codrea, M. C., \& Veiseth-Kent, E. (2012). Changes in protein abundance between tender and tough meat from bovine Longissimus thoracis muscle assessed by isobaric Tag for Relative and Absolute Quantitation (iTRAQ) and 2-dimensional gel electrophoresis analysis. Journal of Animal Science, 90(6), 2035-2043. http://dx.doi.org/10.2527/ jas.2011-4721. PMid:22178849.

Chen, L., Li, Z., Everaert, N., Lametsch, R., \& Zhang, D. (2019). Quantitative phosphoproteomic analysis of ovine muscle with different postmortem glycolytic rates. Food Chemistry, 280, 203209. PMid:30642488.

Chen, L., Liu, J., Kaneko, G., Xie, J., Wang, G., Yu, D., Li, Z., Ma, L., Qi, D., Tian, J., Gong, W., Zhang, K., \& Yu, E. (2020). Quantitative phosphoproteomic analysis of soft and firm grass carp muscle. Food Chemistry, 303, 125367. http://dx.doi.org/10.1016/j. foodchem.2019.125367. PMid:31442901.

Contreras-Castillo, C. J., Lomiwes, D., Wu, G., Frost, D., \& Farouk, M. M. (2016). The effect of electrical stimulation on post mortem myofibrillar protein degradation and small heat shock protein kinetics in bull beef. Meat Science, 113, 65-72. http://dx.doi.org/10.1016/j. meatsci.2015.11.012. PMid:26624792.

D’Alessandro, A., \& Zolla, L. (2013). Meat science: From proteomics to integrated omics towards system biology. Journal of Proteomics, 78, 558-577. PMid:23137709.

Di Luca, A., Elia, G., Hamill, R., \& Mullen, A. M. (2013). 2D DIGE proteomic analysis of early post mortem muscle exudate highlights the importance of the stress response for improved water-holding capacity of fresh pork meat. Proteomics, 13(9), 1528-1544. http:// dx.doi.org/10.1002/pmic.201200145. PMid:23456991.

Faustman, C., Sun, Q., Mancini, R., \& Suman, S. P. (2010). Myoglobin and lipid oxidation interactions: Mechanistic bases and control. Meat Science, 86(1), 86-94. http://dx.doi.org/10.1016/j.meatsci.2010.04.025. PMid:20554121.

Franceschini, A., Szklarczyk, D., Frankild, S., Kuhn, M., Simonovic, M., Roth, A., Lin, J., Minguez, P., Bork, P., von Mering, C., \& Jensen, L. J. (2012). STRING v9. 1: protein-protein interaction networks, with increased coverage and integration. Nucleic Acids Research, 41(D1), D808-D815. http://dx.doi.org/10.1093/nar/gks1094. PMid:23203871.

Gallego, M., Mora, L., Aristoy, M. C., \& Toldrá, F. (2015). Titin-derived peptides as processing time markers in dry-cured ham. Food Chemistry, 167, 326-339. http://dx.doi.org/10.1016/j.foodchem.2014.06.088. PMid:25148995.

Gallego, M., Mora, L., Concepción Aristoy, M., \& Toldrá, F. (2016). The use of label-free mass spectrometry for relative quantification of sarcoplasmic proteins during the processing of dry-cured ham. Food Chemistry, 196, 437-444. http://dx.doi.org/10.1016/j. foodchem.2015.09.062. PMid:26593512.

Guillemin, N., Bonnet, M., Jurie, C., \& Picard, B. (2011). Functional analysis of beef tenderness. Journal of Proteomics, 75(2), 352-365. http://dx.doi.org/10.1016/j.jprot.2011.07.026. PMid:21855665.

Harada, H., Itasaka, S., Kizaka-Kondoh, S., Shibuya, K., Morinibu, A., Shinomiya, K., \& Hiraoka, M. (2009). The Akt/mTOR pathway assures the synthesis of HIF-1a protein in a glucose- and reoxygenationdependent manner in irradiated tumors. The Journal of Biological Chemistry, 284(8), 5332-5342. http://dx.doi.org/10.1074/jbc. M806653200. PMid:19098000.

Hardie, D. G., Ross, F. A., \& Hawley, S. A. (2012). AMPK: a nutrient and energy sensor that maintains energy homeostasis. Nature Reviews. Molecular Cell Biology, 13(4), 251-262. http://dx.doi.org/10.1038/ nrm3311. PMid:22436748. 
He, H., Chen, S., Liang, W., \& Liu, X. (2017). Genome-wide proteomics analysis on longissimus muscles in Qinchuan beef cattle. Animal Genetics, 48(2), 131-140. http://dx.doi.org/10.1111/age.12508. PMid:27646648.

Huang, D. W., Sherman, B. T., \& Lempicki, R. A. (2009). Bioinformatics enrichment tools: paths toward the comprehensive functional analysis of large gene lists. Nucleic Acids Research, 37(1), 1-13. http://dx.doi. org/10.1093/nar/gkn923. PMid:19033363.

Jones, P., Binns, D., Chang, H. Y., Fraser, M., Li, W., McAnulla, C., McWilliam, H., Maslen, J., Mitchell, A., Nuka, G., Pesseat, S., Quinn, A. F., Sangrador-Vegas, A., Scheremetjew, M., Yong, S. Y., Lopez, R., \& Hunter, S. (2014). InterProScan 5: genome-scale protein function classification. Bioinformatics (Oxford, England), 30(9), 1236-1240. http://dx.doi.org/10.1093/bioinformatics/btu031. PMid:24451626.

Joseph, P., Nair, M. N., \& Suman, S. P. (2015). Application of proteomics to characterize and improve color and oxidative stability of muscle foods. Food Research International, 76, 938-945. http://dx.doi. org/10.1016/j.foodres.2015.05.041.

Joseph, P., Suman, S. P., Rentfrow, G., Li, S., \& Beach, C. M. (2012). Proteomics of muscle-specific beef color stability. Journal of Agricultural and Food Chemistry, 60(12), 3196-3203. http://dx.doi. org/10.1021/jf204188v. PMid:22369190.

Kim, N. K., Cho, S., Lee, S. H., Park, H. R., Lee, C. S., Cho, Y. M., Choy, Y. H., Yoon, D., Im, S. K., \& Park, E. W. (2008). Proteins in longissimus muscle of Korean native cattle and their relationship to meat quality. Meat Science, 80(4), 1068-1073. http://dx.doi. org/10.1016/j.meatsci.2008.04.027. PMid:22063838.

Larsson, T., Mørkøre, T., Kolstad, K., Østbye, T. K., Afanasyev, S., \& Krasnov, A. (2012). Gene expression profiling of soft and firm Atlantic salmon fillet. PLoS One, 7(6), e39219. http://dx.doi.org/10.1371/ journal.pone.0039219. PMid:22745718.

Latorre, M. A., Medel, P., Fuentetaja, A., Lázaro, R., \& Mateos, G. G. (2003). Effect of gender, terminal sire line and age at slaughter on performance, carcass characteristics and meat quality of heavy pigs. Animal Science (Penicuik, Scotland), 77(1), 33-45. http://dx.doi. org/10.1017/S1357729800053625.

Li, Z., Li, X., Gao, X., Shen, Q. W., Du, M., \& Zhang, D. (2017). Phosphorylation prevents in vitro myofibrillar proteins degradation by $\mu$-calpain. Food Chemistry, 218, 455-462. http://dx.doi.org/10.1016/j. foodchem.2016.09.048. PMid:27719935.

Lonergan, E. H., Zhang, W., \& Lonergan, S. M. (2010). Biochemistry of postmortem muscle-Lessons on mechanisms of meat tenderization. Meat Science, 86(1), 184-195. http://dx.doi.org/10.1016/j. meatsci.2010.05.004. PMid:20566247.

Malheiros, J. M., Braga, C. P., Grove, R. A., Ribeiro, F. A., Calkins, C. R., Adamec, J., \& Chardulo, L. A. L. (2019). Influence of oxidative damage to proteins on meat tenderness using a proteomics approach. Meat Science, 148, 64-71. http://dx.doi.org/10.1016/j.meatsci.2018.08.016. PMid:30317011.

Malheiros, J. M., Enríquez-Valencia, C. E., Silva Duran, B. O., de Paula, T. G., Curi, R. A., Vasconcelos Silva, J. A. I., Dal-Pai-Silva, M., Oliveira, H. N., \& Chardulo, L. A. L. (2018). Association of CAST2, HSP90AA1, DNAJA1 and HSPB1 genes with meat tenderness in Nellore cattle. Meat Science, 138, 49-52. http://dx.doi.org/10.1016/j. meatsci.2018.01.003. PMid:29331838.

Mao, Y., Hopkins, D. L., Zhang, Y., Li, P., Zhu, L., Dong, P., Liang, R., Dai, J., Wang, X., \& Luo, X. (2016). Beef quality with different intramuscular fat content and proteomic analysis using isobaric tag for relative and absolute quantitation of differentially expressed proteins. Meat Science, 118, 96-102. http://dx.doi.org/10.1016/j. meatsci.2016.03.028. PMid:27064846.
Mora, L., Sentandreu, M. A., \& Toldrá, F. (2010). Identification of small troponin T peptides generated in dry-cured ham. Food Chemistry, 123(3), 691-697. http://dx.doi.org/10.1016/j.foodchem.2010.05.035.

Mora, L., Sentandreu, M. A., \& Toldrá, F. (2011). Intense degradation of myosin light chain isoforms in Spanish dry-cured ham. Journal of Agricultural and Food Chemistry, 59(8), 3884-3892. http://dx.doi. org/10.1021/jf104070q. PMid:21410185.

Ouali, A., Gagaoua, M., Boudida, Y., Becila, S., Boudjellal, A., HerreraMendez, C. H., \& Sentandreu, M. A. (2013). Biomarkers of meat tenderness: present knowledge and perspectives in regards to our current understanding of the mechanisms involved. Meat Science, 95(4), 854-870. http://dx.doi.org/10.1016/j.meatsci.2013.05.010. PMid:23790743.

Paredi, G., Raboni, S., Bendixen, E., Almeida, A. M., \& Mozzarelli, A. (2012). "Muscle to meat" molecular events and technological transformations: the proteomics insight. Journal of Proteomics, 75(14), 4275-4289. http://dx.doi.org/10.1016/j.jprot.2012.04.011. PMid:22543183.

Picard, B., Gagaoua, M., Micol, D., Cassar-Malek, I., Hocquette, J. F., \& Terlouw, C. E. (2014). Inverse relationships between biomarkers and beef tenderness according to contractile and metabolic properties of the muscle. Journal of Agricultural and Food Chemistry, 62(40), 9808-9818. http://dx.doi.org/10.1021/jf501528s. PMid:25175407.

Polati, R., Menini, M., Robotti, E., Millioni, R., Marengo, E., Novelli, E., Balzan, S., \& Cecconi, D. (2012). Proteomic changes involved in tenderization of bovine Longissimus dorsi muscle during prolonged ageing. Food Chemistry, 135(3), 2052-2069. http://dx.doi.org/10.1016/j. foodchem.2012.06.093. PMid:22953957.

Rosa, A. F., Moncau, C. T., Poleti, M. D., Fonseca, L. D., Balieiro, J. C., Silva, S. L., \& Eler, J. P. (2018). Proteome changes of beef in Nellore cattle with different genotypes for tenderness. Meat Science, 138, 1-9. http://dx.doi.org/10.1016/j.meatsci.2017.12.006. PMid:29289712.

STRING. (2020). Retrieved from http://string.embl.de/

Suman, S. P., \& Joseph, P. (2013). Myoglobin chemistry and meat color. Annual Review of Food Science and Technology, 4(1), 79-99. http:// dx.doi.org/10.1146/annurev-food-030212-182623. PMid:23190143.

Tang, J., Faustman, C., Hoagland, T. A., Mancini, R. A., Seyfert, M., \& Hunt, M. C. (2005). Postmortem oxygen consumption by mitochondria and its effects on myoglobin form and stability. Journal of Agricultural and Food Chemistry, 53(4), 1223-1230. http://dx.doi.org/10.1021/ jf048646o. PMid:15713045.

Taye, M., Yoon, J., Dessie, T., Cho, S., Oh, S. J., Lee, H. K., \& Kim, H. (2018). Deciphering signature of selection affecting beef quality traits in Angus cattle. Genes \& Genomics, 40(1), 63-75. http://dx.doi. org/10.1007/s13258-017-0610-z. PMid:29892901.

Te Pas, M. F., Kruijt, L., Pierzchala, M., Crump, R. E., Boeren, S., Keuning, E., Hoving-Bolink, R., Hortós, M., Gispert, M., Arnau, J., Diestre, A., \& Mulder, H. A. (2013). Identification of proteomic biomarkers in M. Longissimus dorsi as potential predictors of pork quality. Meat Science, 95(3), 679-687. http://dx.doi.org/10.1016/j. meatsci.2012.12.015. PMid:23375457.

Wei, Y., Li, X., Zhang, D., \& Liu, Y. (2019). Comparison of protein differences between high-and low-quality goat and bovine parts based on iTRAQ technology. Food Chemistry, 289, 240-249. http:// dx.doi.org/10.1016/j.foodchem.2019.03.052. PMid:30955608.

Wright, S. A., Ramos, P., Johnson, D. D., Scheffler, J. M., Elzo, M. A., Mateescu, R. G., Bass, A. L., Carr, C. C., \& Scheffler, T. L. (2018). Brahman genetics influence muscle fiber properties, protein degradation, and tenderness in an Angus-Brahman multibreed herd. Meat Science, 135, 84-93. http://dx.doi.org/10.1016/j. meatsci.2017.09.006. PMid:28946054. 
Wu, W., Gao, X. G., Dai, Y., Fu, Y., Li, X. M., \& Dai, R. T. (2015). Postmortem changes in sarcoplasmic proteome and its relationship to meat color traits in M. semitendinosus of Chinese Luxi yellow cattle. Food Research International, 72, 98-105. http://dx.doi.org/10.1016/j. foodres.2015.03.030.

Xu, D., Sun, L., Liu, S., Zhang, L., \& Yang, H. (2016). Understanding the heat shock response in the sea cucumber Apostichopus japonicus, using iTRAQ-based proteomics. International Journal of Molecular Sciences, 17(2), 150. http://dx.doi.org/10.3390/ijms17020150. PMid:26861288.

Yang, Y., Han, L., Yu, Q., Gao, Y., Song, R., \& Zhao, S. (2020). Phosphoproteomic analysis of longissimus lumborum of different altitude yaks. Meat Science, 162, 108019. http://dx.doi.org/10.1016/j. meatsci.2019.108019. PMid:31887536.
Zhang, B., \& Liu, J. Y. (2017). Serine phosphorylation of the cotton cytosolic pyruvate kinase GhPK6 decreases its stability and activity. FEBS Open Bio, 7(3), 358-366. http://dx.doi.org/10.1002/2211-5463.12179. PMid:28286731.

Zhang, L., Sun, B., Xie, P., Li, H., Su, H., Sha, K., Huang, C., Lei, Y., Liu, X., \& Wang, H. (2015). Using near infrared spectroscopy to predict the physical traits of Bos grunniens meat. Lebensmittel-Wissenschaft + Technologie, 64(2), 602-608. http://dx.doi.org/10.1016/j.lwt.2015.06.022.

Zuo, H. X., Han, L., \& Yu, Q. (2017). Proteomics and bioinformatics analyses of differentially expressed proteins in yak and beef cattle muscle. Nongye Jixie Xuebao, 48(4), 313-320.

Zuo, H. X., Han, L., Yu, Q., Niu, K., Zhao, S., \& Shi, H. (2016). Proteome changes on water-holding capacity of yak longissimus lumborum during postmortem aging. Meat Science, 121, 409-419. http://dx.doi. org/10.1016/j.meatsci.2016.07.010. PMid:27448195. 